\title{
Contributing Factors in the Tuberculosis Care Cascade in India: A Systematic Literature Review
}

\author{
Sandul Yasobant (iD) ${ }^{1,2}$ \\ Priya Bhavsar' \\ Pachillu Kalpana' \\ Farjana Memon' \\ Poonam Trivedi \\ Deepak Saxena (1D) ${ }^{1-3}$
}

'Department of Epidemiology, Indian Institute of Public Health Gandhinagar (IIPHG), Gandhinagar, 382042, India; ${ }^{2}$ Center for One Health Education, Research, and Development (COHERD), Indian Institute of Public Health Gandhinagar (IIPHG), Gandhinagar, 382042, India; ${ }^{3}$ Jawaharlal Nehru Medical College, Datta Meghe Institute of Medical Sciences (DMIMS), Wardha, 442004, India
Correspondence: Deepak Saxena Indian Institute of Public Health Gandhinagar, Opp. Air Force Head Quarters, Nr. Lekawada, Gandhinagar, 382042, Gujarat, India

Tel +9I-93273967I7

Email ddeepak72@iiphg.org

\begin{abstract}
Tuberculosis (TB) care cascade is a recently evolved care model for patient retention across the sequential stages of care for a successful treatment outcome. The care cascade is multi-folded and complex in setting where the health system is reforming for its resilience. India, one of the countries with the highest burden of tuberculosis mortality and morbidity, is not an exception to this complexity. With the diverse challenges in the Indian health system and societal diversity, it is essential to understand the factors contributing to this TB care cascade. Thus, this study aims to map all the contributing factors to the TB care cascade in India. Further, it also captures the different patterns of factors explored so far in different countries' regions. This systematic literature review was conducted between October 2020 and February 2021 in India using PubMed databases, Web of Science, and Google Scholar. Two reviewers extracted the data from eligible studies to summarize and tabulate important findings. Data were extracted and tabulated for study design, location of the study, type of TB patients, methodological approach, system side challenges, and demand-side challenges in the study's findings. Out of 692 initial hits from the literature search, 28 studies were finally included to synthesize evidence in this review as per the inclusion and exclusion criteria. This review provides an insight into different factors such as the system-side (health workforce, institutional) and the demand-side (individual, societal) contributing towards the care cascade. The prime factors reflected in most of the studies were socio-economic condition, disease awareness, myths/beliefs, addictions among the demandside factors and accessibility, the attitude of the healthcare staff, delay in referral for diagnosis among the system-side factors. The accountability for addressing these diverse factors is recommended to close the gaps in the TB care cascade.
\end{abstract}

Keywords: care-seeking, care cascade, factors, tuberculosis, India

\section{Introduction}

Among other global burdens of diseases, the estimated tuberculosis (TB) cases are 130 cases/100,000 population globally, ${ }^{1}$ and $131 / 100,000$ population in India. ${ }^{2}$ The Global TB Report 2020 indicates that India has a dual burden of tuberculosis $(26 \%)$ and multidrug-resistant (MDR)/rifampicin-resistant $(27 \%){ }^{3}$ About $26 \%$ of the worldwide incident cases and $31 \%$ of the global TB deaths were contributed by India. ${ }^{4}$ In India, during the Union Budget 2017-2018, with a commitment to reach the 2030 United Nations (UN) Sustainable Development Goals target, the Government has announced its plan to end the TB epidemic by $2025 .^{5}$ India's TB control program got rechristened to National Tuberculosis Elimination Programme (NTEP) from the Revised National Tuberculosis Control Programme (RNTCP) on January 1st, 2020. The longest battle against this disease in India started as National 
TB Control Programme (NTCP) in 1962 and continued with two phases of RNTCP from 1997 through $2019 .^{6}$ Currently, NTEP functions as a leading element of the National Health Mission (NHM) and provides technical and managerial leadership to anti-tuberculosis activities in the country.

One among other key gaps in TB control is the "missing millions": 3 in 10 people developing TB globally are either not diagnosed and treated or are not notified of national tuberculosis programs. ${ }^{7}$ Five most countries accounted for more than half of the global gap: India (17\%), Nigeria (11\%), Indonesia (10\%), Pakistan (8\%), and the Philippines (7\%). ${ }^{1}$ It is equally important both to understand the absolute number of individuals achieving a point in care during the TB treatment and a gap (i.e., the difference between steps, representing individuals with suboptimal outcomes). ${ }^{8,9}$ The diverse gaps have been identified globally ${ }^{10,11}$ and in India. ${ }^{10}$ The 'cascade of care' is a useful model for evaluating care delivery by a health system for a specific disease. ${ }^{11}$ The care cascade behavior by the patients refers to their respective actions to facilitate them to treat or manage their symptoms. ${ }^{12}$ It is a complicated process that entails patients interpretation of their symptoms, their health behavior/attitude, and then opting for treatment actions to adapt depending on the accessibility (financial and physical). ${ }^{12}$ Since TB is usually not a lifelong disease and can be cured with appropriate therapy, we have used the term "TB care cascade" in this review as a continuum process.

India's efforts towards TB elimination operationalized with four strategic pillars of "Detect - Treat -Prevent Build" (DTPB). ${ }^{5}$ The TB care cascade starts with the onset of symptoms and access to seek health-care services either from the public or private. Hence, the early accurate diagnosis of TB and enhancing case finding efficiency, identification of presumptive TB cases at the first point of care, and linking them to the best available diagnostic tests are of paramount importance. With a three-tier laboratory network system for the diagnosis of TB, the National and/or intermediate reference laboratories and Designated Microscopy Centres are undertaking the sputum smear microscopy for primary diagnosis of drug-sensitive TB and rapid molecular test for the diagnosis of drug resistance, including the tools like Chest X-Ray as a screening method to improve the sensitivity of detecting pulmonary TB, followed by a high sensitivity diagnostic test like CBNAAT as a tool for universal DST. Followed the confirmatory tests, DSTB patients have provided daily fixed- dose combinations (FDCs) as per patient's weight band with augmented continuation phase and intensified treatment support systems using ICT and DRTB patients follow the shorter or longer regimen as per the resistant pattern. Followed treatment the activities like, adherence monitoring, Direct Benefits Transfer (DBT) and initial and frequent follow-up counselling of the patient and family members, supervision of treatment by a trained treatment supporter, retrieval of treatment interrupters, screening for adverse reactions, appropriate social support scheme, psycho-social support, co-morbidity management, and followup laboratory investigations were being conducted as part of NTEP guidelines. ${ }^{5,13}$ All the events of the cascade are captured out with an innovative and visionary electronic recording and reporting system (Nikshay). ${ }^{14}$

The TB care cascade is a product of cognitive and noncognitive factors, not only from the patients but also from the health system, which calls for contextual analysis on understanding the multiplying contributing factors. ${ }^{12}$ Although different studies have been conducted so far in India on capturing the contributing risk factors on the care cascade of TB patients, there is a lack of a review that compiles all the factors. This enforces to study and map all the contributing factors to the TB care-seeking pathways in India. Further, it also captures the different patterns of factors explored so far in different countries' regions. The findings of this study will assist in understanding the diverse and potential contributing factors and aid future research on suggesting the least explored factors, which might have (in)direct impact on the care cascade.

\section{Methods}

This systematic literature review was conducted between October 2020 to date (February 2021) in India.

\section{Search Terms and Strategies}

A broad search was conducted through PubMed, Web of Science, and Google Scholar (first 10 web pages) using keywords like tuberculosis and care-seeking pathways. (((tuberculosis[Title/Abstract]) OR (TB[Title/Abstract])) OR (tubercul*[Title/Abstract])) OR ("tuberculosis”[MeSH Terms]) AND ((“health behaviour"[Title/Abstract]) OR (access[Title/Abstract])) OR (pathway[Title/Abstract])) OR (barrier[Title/Abstract])) OR (“care seeking”[MeSH Terms]). Further, the search was limited to country India along with the above-mentioned search arms. Additional key references were identified from the bibliography of relevant studies. 


\section{Inclusion and Exclusion Criteria}

We have included studies that assessed and/or documented the factors that directly or indirectly affect the careseeking pathway of the TB patients in India, irrespective of study design, geographic location within India, type of TB, age, gender, or type of treatment. Only published studies in the English language were considered for inclusion. Because of resource limitations, we did not include studies that were published in other languages. Only the articles published on or after 2010 to date were included in the review irrespective of the design (both quantitative and qualitative).

\section{Quality Assurance}

There were three reviewers; two independently searched the database, and the third reviewer independently screened the retrieved studies against the inclusion criteria, initially based on title and abstract and then based on full texts. Another reviewer also reviewed approximately $20 \%$ of these studies to validate the inclusion of studies. Disagreements were resolved through discussion.

\section{Data Extractions}

Two reviewers extracted the data from eligible studies to summarize and tabulate important findings. Data were extracted and tabulated about study design, location of the study, type of TB patients, methodological approach, system side challenges, and demand-side challenges in the study's findings. The contributing factors were synthesized either quantitatively or qualitatively as expressed in the included studies. In some studies, the risk factors were expressed with an absolute value; however, it was not quantified in this review. Therefore, all the risk factors mentioned contributing to the care cascade were extracted for this review.

\section{Study Definitions}

A risk factor is a characteristic, condition, or behaviour that increases the probability of getting a disease or injury. Risk factors are presented individually (personal) or presented socially (social), or environmental. The risk factors interact with one another and often coexist. ${ }^{15}$ In this study, a contributing factor is equally considered as a risk factor, as authors hypothesized that each contributing factor has some impact (either direct or indirect) on the outcome of the care cascade. In this study, the risk factors synthesis was conducted in two broad categories, ie, system-side factors (factors from the service providers or the organizational factors) and the demand-side factors (factors at the individual patient level or at the societal level including family)

Delay is measured from the time of onset of the first symptoms to the time of treatment initiation and is categorized by patient and health system delay. Patient delay is the time between the onset of the first TB symptom to the time of seeking care, while health system delay is the duration between the first contact with the health facility to the time of initiating treatment. The health system delay could be of diagnostic delay (ie, between the first formal consultation to the confirmatory diagnosis) or treatment delay (ie, confirmatory diagnosis to the initiation of treatment). ${ }^{16}$

\section{Results}

\section{General Characteristics of Reviewed Studies \\ Search results}

We have retrieved 692 non-duplicated hits from the literature search in PubMed, Web of Science, and Google Scholar (first 10 web pages). After screening by title and abstract, 39 articles remained. Twenty-eight studies were finally included for the synthesis of evidence in this review (Figure 1).

\section{Search Results by Research Setting}

Considering the geographic region of the study in India, about 9 studies were conducted in Maharashtra, 5 studies in Tamil Nadu and Puducherry, 3 in Madhya Pradesh, especially Bhopal, and 2 in Andhra Pradesh, and 1 study on nine different states across the country. Further, 1 study was conducted in Bihar, Karnataka, Delhi, Sikkim, Punjab, Gujarat, as shown in Table 1.

\section{Search Results by Publication Year}

As per the inclusion criteria, 2010 onward studies were included in this review. Table 1, represents the frequency distribution of included literature by publication year. There were the highest 5 publications in the year 2019, followed by 4 in 2017 and the least of 1 in 2011 and 2014.

\section{Search Results by the Type of Study}

The 28 included studies comprised 19 quantitative, 6 qualitative, and 3 mixed-method studies. As shown in Table 1, there were three key focus on samples in the included studies, ie, system-side (actors from the TB care program) or the demand-side (varieties of TB patients) or mixed-sample (both from system and demand-side). There were 5 studies 


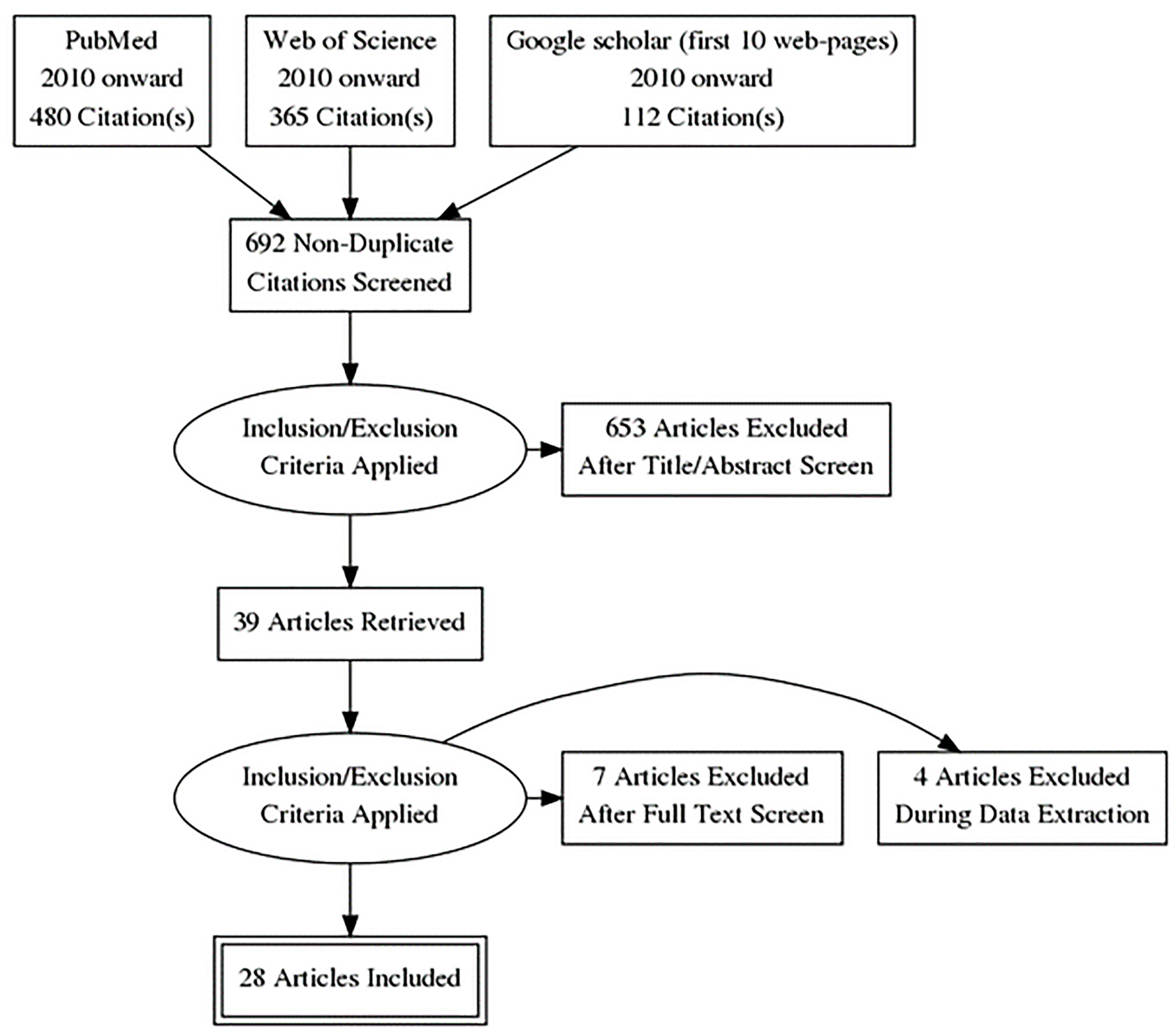

Figure I Article search and selection process for the systematic literature review on contributing factors in the Tuberculosis care cascade in India.

that investigated the problem with mixed samples, whereas three studies exclusively focused on the system-side analysis and others focused exclusively on the demand-side analysis. The system-side samples were mostly recruited for the qualitative interviews from both the public and private providers. Among the demand-side samples, there were defaulter TB patients, pulmonary TB patients (on treatment/ completed), exclusively women TB patients, MDRTB (who were reported as Lost To Follow Up), pediatric TB cases $(\leq 14$ years), TB patients who had not responded to the treatment. One study also looked into the secondary data of presumptive TB cases and combined it with the interviews of sampled TB cases. The samples of the quantitative studies were ranged from a minimum of 50 to a maximum of 1667 TB patients.
The secondary data of TB patients were conducted with a maximum of 4979 cases. Similarly, the included studies had conducted a minimum of 10 interviews to a maximum of 33 interviews among the selected TB patients. Further, focused group discussions were also conducted.

All the included studies were synthesized either having at least one factor either from the system-side (health workforce and institutional) or demand-side (personal or societal). Thirteen studies mentioned health workforce factors, and 10 mentioned institutional factors. Similarly, 25 studies mentioned at least one personal factor, and 10 studies mentioned societal factors. Table 1 indicates the summarized view of the included studies for the synthesis with their characteristics and dimensions. 
Table I Descriptive Characteristics and Their Scope of the Included Studies on TB Care Cascade as Evidenced in the Review Conducted in October 2020 and February 2021 in India

\begin{tabular}{|c|c|c|c|c|c|c|}
\hline Sr. No. & Study ID & $\begin{array}{l}\text { Study } \\
\text { Setting }\end{array}$ & Study Design & $\begin{array}{l}\text { Study } \\
\text { Method }\end{array}$ & Participants & Sample Size \\
\hline I & $\begin{array}{l}\text { Bhattacharya } \\
\text { et al, } 2018^{17}\end{array}$ & West Bengal & Descriptive & Qualitative & $\begin{array}{l}\text { Defaulter TB Patients and } \\
\text { providers }\end{array}$ & $\begin{array}{l}\text { I4 defaulter patients, } 30 \text { DOTS } \\
\text { providers, and } 4 \text { staff members of } \\
\text { TU }\end{array}$ \\
\hline 2 & $\begin{array}{l}\text { Bagchi et al, } \\
2010^{18}\end{array}$ & Mumbai & Cross sectional & Quantitative & $\begin{array}{l}\text { Pulmonary TB patients (on } \\
\text { treatment) }\end{array}$ & 538 patients \\
\hline 3 & $\begin{array}{l}\text { McAurthur } \\
\text { et al, } 2016^{19}\end{array}$ & Bhopal & Cross-sectional & Mixed & $\begin{array}{l}\text { Tuberculosis patients } \\
\text { (Women) and healthcare } \\
\text { workers }\end{array}$ & $\begin{array}{l}\text { Quantitative: Diagnostic } \\
\text { Microscopy Laboratory Register } \\
(n=I 2 I) \text { and district report } \\
(n=26 I) \text { of Bhopal } \\
\text { Qualitative: I } 3 \text { patients and } 6 \\
\text { Healthcare workers( } \\
\text { DTO, I Physician, } 2 \text { TB nurses and } \\
2 \text { NGO staff members) }\end{array}$ \\
\hline 4 & $\begin{array}{l}\text { Shewade } \\
\text { et al, } 2018^{20}\end{array}$ & Bhopal & Descriptive & Qualitative & $\begin{array}{l}\text { Key informants involved in } \\
\text { programmatic management } \\
\text { of DR-TB }\end{array}$ & $\begin{array}{l}10 \text { In-depth interviews and } 2 \\
\text { Focussed group discussion }\end{array}$ \\
\hline 5 & $\begin{array}{l}\text { Deshmukh } \\
\text { et al, } 2015^{21}\end{array}$ & Nagpur & Descriptive & Qualitative & $\begin{array}{l}\text { MDR- TB patients } \\
\text { (reported as LTFU) and } \\
\text { providers }\end{array}$ & $\begin{array}{l}20 \text { MDRTB patients reported as } \\
\text { LTFU and } 10 \text { treatment providers }\end{array}$ \\
\hline 6 & $\begin{array}{l}\text { Shewade } \\
\text { et al, } 2017^{22}\end{array}$ & Bhopal & $\begin{array}{l}\text { Retrospective } \\
\text { Cohort }\end{array}$ & Quantitative & $\begin{array}{l}\text { Presumtive MDR TB } \\
\text { patients }\end{array}$ & 770 patients (from the records) \\
\hline 7 & $\begin{array}{l}\text { Shringarpure } \\
\text { et al, } 2015^{23}\end{array}$ & Gujarat & $\begin{array}{l}\text { Retrospective } \\
\text { Cohort }\end{array}$ & Quantitative & $\begin{array}{l}\text { Registered patient at DR- } \\
\text { TB site }\end{array}$ & 796 patients \\
\hline 8 & $\begin{array}{l}\text { Valvi et al, } \\
2019^{24}\end{array}$ & Pune & Cross-sectional & Quantitative & $\begin{array}{l}\text { Children initiated anti- TB } \\
\text { treatment ( } \leq 14 \text { years) }\end{array}$ & 89 patients \\
\hline 9 & $\begin{array}{l}\text { Nimbarte } \\
\text { et al, 20I } \mathrm{I}^{25}\end{array}$ & Maharashtra & Cross-sectional & Quantitative & $\begin{array}{l}\text { Pulmonary Tuberculosis } \\
\text { patient (newly diagnosed) }\end{array}$ & 189 patients \\
\hline 10 & $\begin{array}{l}\text { Mistry et al, } \\
2016^{26}\end{array}$ & Mumbai & $\begin{array}{l}\text { Retrospective } \\
\text { survey }\end{array}$ & Quantitative & $\begin{array}{l}\text { Pulmonary Tuberculosis } \\
\text { patient }\end{array}$ & 76 patients \\
\hline II & $\begin{array}{l}\text { Velavan et al, } \\
2019^{27}\end{array}$ & Puducherry & Cross-sectional & Mixed & Healthcare workers & $\begin{array}{l}\text { Quantitative: TB patient register } \\
\text { Qualitative: } 10 \text { In-depth interviews } \\
\text { and two Focussed I 2group } \\
\text { discussion }\end{array}$ \\
\hline 12 & $\begin{array}{l}\text { Helfinstein } \\
\text { et al, } 2020^{28}\end{array}$ & Chennai & Prospective study & Quantitative & $\begin{array}{l}\text { TB presumptive or pre- } \\
\text { presumptive }\end{array}$ & 1667 \\
\hline 13 & $\begin{array}{l}\text { Shewade } \\
\text { et al, } 2015^{29}\end{array}$ & Puducherry & $\begin{array}{l}\text { Retrospective } \\
\text { cohort study }\end{array}$ & Mixed & $\begin{array}{l}\text { Key informants involved in } \\
\text { programmatic management }\end{array}$ & $\begin{array}{l}\text { Quantitative: Record review of } \\
\text { MDR TB patient }(n=34 I) \\
\text { Qualitative: Key informant } \\
\text { interviews }\end{array}$ \\
\hline 14 & $\begin{array}{l}\text { Singhi et al, } \\
2014^{30}\end{array}$ & Sikkim & $\begin{array}{l}\text { Retrospective } \\
\text { cohort study }\end{array}$ & Quantitative & $\begin{array}{l}\text { TB patients (who had not } \\
\text { responded to the treatment }\end{array}$ & $\begin{array}{l}\text { I } 508 \text { patients enrolled in RNTCP } \\
\text { and } 42 \text { patients }\end{array}$ \\
\hline
\end{tabular}

(Continued) 
Table I (Continued).

\begin{tabular}{|c|c|c|c|c|c|c|}
\hline Sr. No. & Study ID & $\begin{array}{l}\text { Study } \\
\text { Setting }\end{array}$ & Study Design & $\begin{array}{l}\text { Study } \\
\text { Method }\end{array}$ & Participants & Sample Size \\
\hline 15 & $\begin{array}{l}\text { Dhaked et al, } \\
2019^{31}\end{array}$ & Delhi & Cross-sectional & Quantitative & Pediatric TB patients & |4| patients \\
\hline 16 & $\begin{array}{l}\text { Thomas et al, } \\
2020^{32}\end{array}$ & Chennai & Descriptive & Qualitative & $\begin{array}{l}\text { Pre-treatment loss to } \\
\text { follow up patients or family } \\
\text { members and healthcare } \\
\text { workers }\end{array}$ & $\begin{array}{l}6 \text { Focussed group discussion } \\
\text { (HCW) } \\
33 \text { Patient interview }\end{array}$ \\
\hline 17 & $\begin{array}{l}\text { Van Ness } \\
\text { et al, } 2017^{33}\end{array}$ & $\begin{array}{l}\text { Puducherry } \\
\text { and } \\
\text { Tamilnadu }\end{array}$ & $\begin{array}{l}\text { Cross-sectional } \\
\text { Study }\end{array}$ & Quantitative & Pulmonary TB patients & 501 patients \\
\hline 18 & $\begin{array}{l}\text { Secretary } \\
\text { et al, } 2018^{34}\end{array}$ & Chhattisgarh & $\begin{array}{l}\text { Retrospective } \\
\text { cohort study }\end{array}$ & Quantitative & Secondary data & 4979 patients \\
\hline 19 & $\begin{array}{l}\text { Paul et al, } \\
2012^{35}\end{array}$ & $\begin{array}{l}\text { West bengal } \\
\text { and Andhra } \\
\text { Pradesh }\end{array}$ & $\begin{array}{l}\text { Retrospective } \\
\text { cohort study } \\
\text { followed by } \\
\text { cross-sectional }\end{array}$ & Quantitative & Pulmonary TB patients & $\begin{array}{l}2027 \text { patients followed by } \\
\text { interview of random } 150 \text { patients }\end{array}$ \\
\hline 20 & $\begin{array}{l}\text { Tripathy et al, } \\
2013^{36}\end{array}$ & Punjab & Cross sectioanl & Quantitative & $\begin{array}{l}\text { Secondary data } \\
\text { (presumptive TB patients) }\end{array}$ & 1918 patients \\
\hline 21 & $\begin{array}{l}\text { Tamhane } \\
\text { et al, } 2012^{37}\end{array}$ & Mumbai & Cross-sectional & Quantitative & Pulmonary TB patients & I50 patients \\
\hline 22 & $\begin{array}{l}\text { Yerramilli } \\
\text { et al, } 2019^{38}\end{array}$ & Multi-site & Prospective study & Quantitative & TB patients & 50 patients \\
\hline 23 & $\begin{array}{l}\text { Yellappa et al, } \\
2017^{39}\end{array}$ & Karnataka & Descriptive & Qualitative & TB patients and providers & $\begin{array}{l}33 \text { TB patients and } 38 \text { Private } \\
\text { providers }\end{array}$ \\
\hline 24 & $\begin{array}{l}\text { Vijay et al, } \\
2010^{40}\end{array}$ & Multi-site & $\begin{array}{l}\text { Retrospective } \\
\text { cohort study }\end{array}$ & Quantitative & Pulmonary TB patient & 389 defaulted and 540 completed \\
\hline 25 & $\begin{array}{l}\text { Mistry et al, } \\
2017^{10}\end{array}$ & Patna & Cross-sectional & Quantitative & Pulmonary TB patients & 64 patients \\
\hline 26 & $\begin{array}{l}\text { Bhattacharya } \\
\text { et al, } 2019^{41}\end{array}$ & Mumbai & Descriptive & Qualitative & DR- TB patients & 46 patients \\
\hline 27 & $\begin{array}{l}\text { Kulkarni et al, } \\
2013^{42}\end{array}$ & Mumbai & Cross-sectional & Quantitative & Pulmonary TB patients & $\begin{array}{l}\text { I } 56 \text { patients from } 24 \text { DOTS } \\
\text { centers }\end{array}$ \\
\hline 28 & $\begin{array}{l}\text { Konda et al, } \\
2012^{43}\end{array}$ & Mumbai & Cross-sectional & Quantitative & Pulmonary TB patients & 122 patients \\
\hline
\end{tabular}

Abbreviations: DOTS, Directly Observed Therapy Shortcourse; DTO, District TB Officer; HCW, healthcare workers; LTFU, lost-to-follow up; NGO, Non-Governmental Organizations; RNTCP, Revised National Tuberculosis Control Program; TU, TB Unit.

\section{System-Side Contributing Factors (Health Providers/Organizational)}

The system-side factors are narrated at the provider level or the health system organizational/institutional level. The impact on the care cascade has documented either challenge at the health workforce or the organizational level with a broader scope. The most contributing factors that were documented at the health workforce level are overburdened manpower working in the $\mathrm{TB}$ program, ${ }^{20}$ inappropriate referral by private providers, ${ }^{17,22}$ unqualified practitioners considered as informal 
providers, ${ }^{19}$ delay in referral for TB diagnosis from the private facilities, ${ }^{10,19,26}$ inadequate trained manpower, ${ }^{27}$ misinterpretation of provisional diagnosis, ${ }^{26}$ etc. In addition to it, the health-care staff attitude and behaviour ${ }^{21,24,26}$ and poor counseling capacities ${ }^{18,21}$ were also found to be a risk factor such as health-care providers not explaining problems of stopping the medicine, or inappropriate attitude of the providers leading to the misconception or delays in care-seeking. This signifies that managerial and psychological skills are equally important in addition to the technical issues of human resources, lab diagnosis capacity, or the providers' knowledge. In brief, the patient-provider interaction was a significant factor in the care cascade and outcome of the TB patients in most of the studies.

Beyond the health workforce, the other sphere of contributing factors from the system side were broader challenges at the supply chain, technological issues, transportation of samples, and capacity building, mostly at the institutional level or health system as a whole. Among others, the factors were reflected as a poor support system for Directly Observed Therapy (DOT) provider, unavailability of courier system, ${ }^{20}$ unavailability of referral forms, ${ }^{20}$ unaccountability in tracking patients, ${ }^{20}$ the ratio of $\mathrm{TB}$ patients to the $\mathrm{TB}$ units, the complexity of navigating within the tertiary health center and the grassroots health centers, inadequate laboratory and diagnostic facilities, ${ }^{20}$ transportation of drugs from peripheral health institute to DOT provider, ${ }^{18,20,35}$ etc.

\section{Demand-Side Contributing Factors (Individual/Social)}

At the individual level, diverse factors were documented. On a broader scale, poverty, ${ }^{17,32}$ unemployment and financial constraints, ${ }^{10,17,24-27,31,33,38}$ migration, ${ }^{26}$ illiteracy ${ }^{40}$ stands as major factors, as documented in most of the studies. Followed which, awareness about the disease/ availability of services, ${ }^{17,21,24,25,28,40}$ ignorance or selftreating symptoms, ${ }^{10,18,20,21,24,26,28}$ myths/wrong beliefs, shame/confidentiality issues ${ }^{21}$ found to be significant contributors. In addition to it, personal behaviours like addiction to alcohol, tobacco, smoking ${ }^{17,18,21,26-29,32,33,40}$ also contribute to the care cascade. Other personal factors that remained are fear of diagnosis, fear of the outcome measures, fear of loss of occupation, fear of society, ${ }^{19,27}$ etc. Focusing on the individual factors with more specific to TB treatment, factors like the inability to collect the medicine, ${ }^{17}$ travel-related (transportation, cost), ${ }^{18,31}$ selfwithdrawal once the symptoms subside, ${ }^{18,19}$ inability to produce sputum, ${ }^{20}$ past unpleasant experience of DOT, ${ }^{20}$ multiple visits/consultation of health-care providers, ${ }^{23,32}$ delays in approaching provider after leaving a previous provider, ${ }^{10,26,35}$ delays in getting the test done and collecting results, self-refusal to get the test done, ${ }^{10,26}$ dissatisfied with services, ${ }^{40}$ cost of diagnosis and treatment ${ }^{38}$ etc. remained contributing factors towards the outcome of the TB care cascade. In addition to it, some of the factors specific to the TB drugs also narrated in some of the studies, among others high pill burden, ${ }^{17}$ adverse drug and treatment effects, ${ }^{38}$ long duration of therapy ${ }^{17,18}$ remained as the generic concern of the TB patients.

Some of the social factors, which are more contextspecific, should be addressed to improve the TB cascade and other public health challenges. Factors like stigma, ${ }^{19,20,38}$ discrimination, ${ }^{20}$ lack of family to the social support, ${ }^{27,29,32}$ negative counselling by family/friends ${ }^{10}$ also contribute largely to the care cascade. Table 2 summarizes all the factors (both system-side and demand-side) as evidenced in the synthesis contributing to the care cascade.

\section{Integral Contributing Factors and Delays}

The delays were discussed either as patient delays or the health system delay (both the diagnostic and treatment delays). Both the system-side and demand-side factors were documented as contributing factors for all these three types of delays. The only exception was there were no system-side factors that contribute to the patient delay; however, the attitude/behaviour of health-care staff and inadequate facility might be indirectly related. Among the demand-side factors, ignoring symptoms/hope that symptoms would go away on their own (denial and concealment), ${ }^{19}$ self-medication/self-treating symptoms from nearby private chemists/home remedies or use of traditional healer, ${ }^{19,24,26,33,39,42}$ lack of awareness about the disease and the services, ${ }^{24}$ poor socio-economic conditions, ${ }^{24,26,33}$ fear to get diagnosed or fears for social isolation, ${ }^{26}$ addictions $^{26,28,33}$ and migration ${ }^{42}$ mostly contribute towards the patient delay. Similarly, factors like visit to multiple health-care providers, ${ }^{19,24,26,33}$ previous expenditure $^{43}$ or financial constraint, ${ }^{26}$ access/residing in a non-DMC/PHI area, ${ }^{35}$ refusal/self-medications, ${ }^{26}$ denial $^{26,42}$ and migration ${ }^{26}$ are among other demand-side factors evidenced for the diagnostic delay of the care cascade. From the system-side factors, in-appropriate 
Table 2 Summarized System-Side and Demand-Side Contributory Factors to the TB Care Cascade as Evidenced in the Review Conducted in October 2020 and February 2021 in India

\begin{tabular}{|c|c|}
\hline \multicolumn{2}{|l|}{ System-Side Factors } \\
\hline Health workforce level & Institutional/ system level \\
\hline $\begin{array}{l}\text { Overburdened manpower } \\
\text { Insufficient referral }^{17,22} \\
\text { Unqualified practitioner } \\
\text { Delay in referral for TB diagnosis } \\
\text { Inadequate trained manpower }^{27} \\
\text { Knowledge level for identification of patients eligible for } \mathrm{DST}^{20} \\
\text { Lack of assured specimen transport and tracking }^{20} \\
\text { Inadequate history taking }^{24} \\
\text { Misinterpretation of provisional diagnosis } \\
\text { staffs }^{21,24,26} \text { Attitude and behaviour of } \\
\text { Poor counselling capacities } \\
\end{array}$ & $\begin{array}{l}\text { Poor support system for DOT provider } \\
\text { Unavailability of courier system to transport specimen from DMCs for } \\
\mathrm{DST}^{20} \\
\text { Non-availability of referral forms }{ }^{20} \\
\text { Lack of accountability in tracking }^{20} \\
\text { Inadequate laboratory and diagnostic facilities for DST } \\
\text { Transportation of drugs from peripheral health institute to DOT } \\
\text { provider }^{20} \\
\text { Technical issues of internet }^{20}\end{array}$ \\
\hline \multicolumn{2}{|l|}{ Demand-Side Factors } \\
\hline Individual-level & Societal level \\
\hline 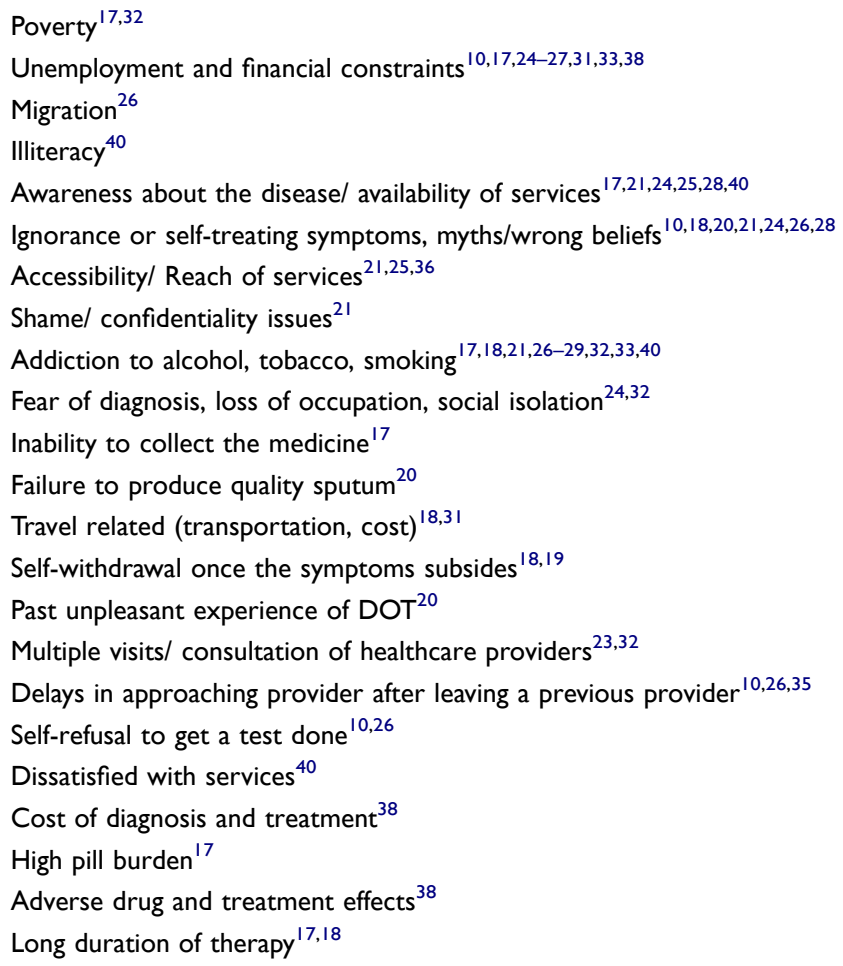 & $\begin{array}{l}\text { Stigma } \\
\text { Discrimination }^{190} \\
\text { Lack of family to the social support }^{27,29,32} \\
\text { Negative counseling by family/ friends }{ }^{10}\end{array}$ \\
\hline
\end{tabular}

Abbreviations: DMC, Designated Microscopy Centre; DOT, Directly Observed Therapy; DST, Drug susceptibility testing.

provisional diagnosis/screening, ${ }^{24,26}$ cross-referral issues and especially from the informal providers, ${ }^{19,26,39}$ improper advising for relevant tests for diagnosis of $\mathrm{TB}^{26}$ and delayed collection of reports of sputum microscopy ${ }^{42}$ found to be significant contributing factors.

Similarly, at the treatment level delay, among others provider's poor patient-centric behaviour, ${ }^{26}$ referral by the diagnostic provider to another provider for the initiation of treatment, ${ }^{26}$ delay in reporting, ${ }^{42}$ giving long periods of symptomatic treatment to patients ${ }^{26}$ and among demandside factors; multiple visits before initiation of treatment, ${ }^{24,26,37,44}$ migration, ${ }^{26,42,43}$ physical access to a health facility ${ }^{36}$ found to be major contributing factors. Figure 2 summarizes all the factors (both system and 


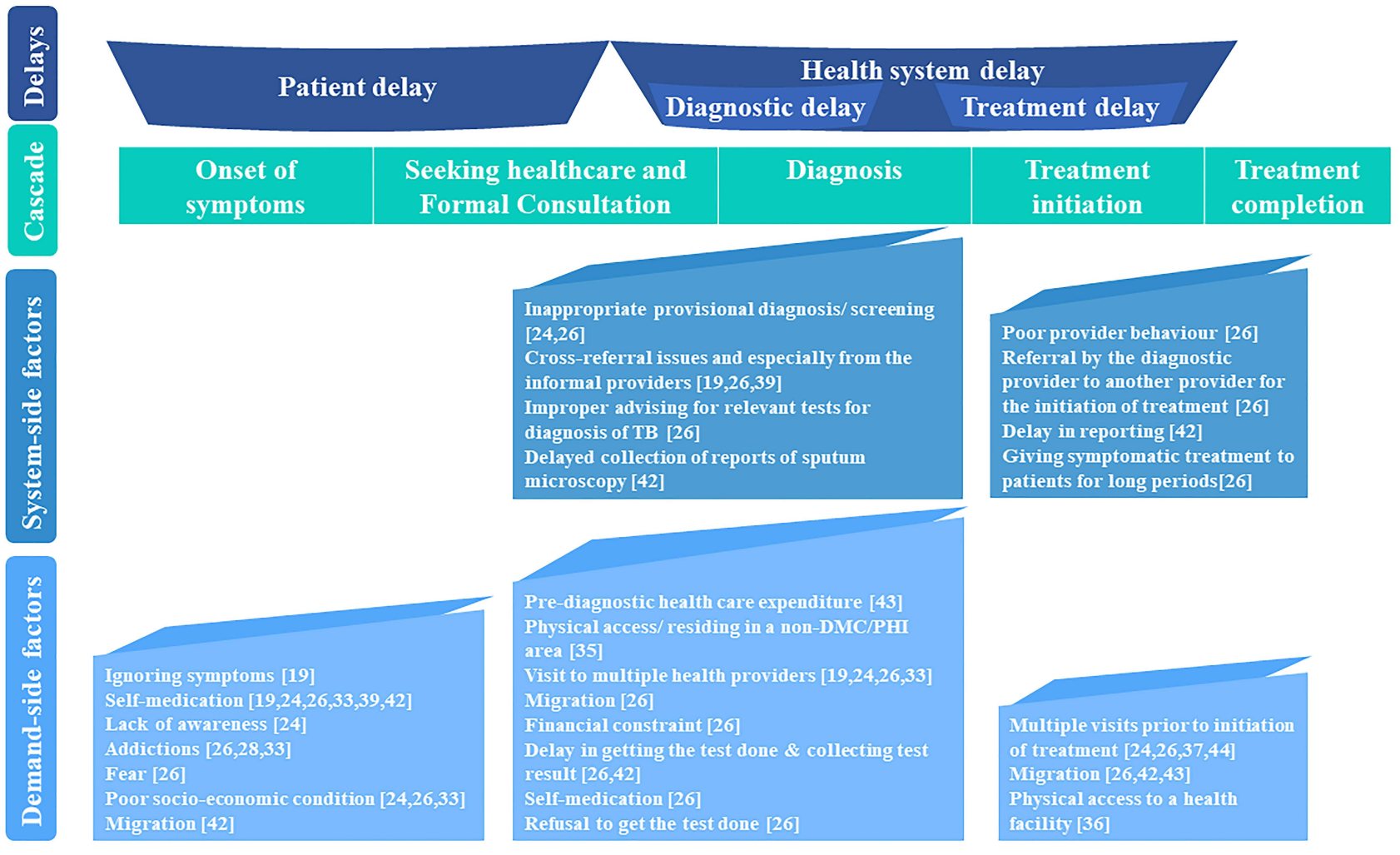

Figure 2 Integrating contributory factors to the delays of the TB care cascade as evidenced in the review conducted in October 2020 and February 2021 in India.

demand-side) that contributed to different phases of delay in the care cascade.

\section{Discussion}

With a view to achieve the ambitious targets set out in the End TB Strategy or to improve the TB care cascade, we need to understand the dynamics of contributing factors. Only addressing or strengthening the system factors might not be sufficient enough to address this complex care cascade.

In this synthesis, although the target was not to quantify the risk factors, there are few prominent risk factors that were reflected in most of the studies. Factors like poor-socio economic conditions, ${ }^{10,17,24-27,31,33,38}$ disease awareness, ${ }^{17,21,24,25,28,40}$ ignorance/myths, ${ }^{10,18,20,21,24,26,28}$ addictions, ${ }^{17,18,21,26-29,32,33,40}$ stigma, ${ }^{19,20,38}$ family support $^{27,29,32}$ found to be the major contributing factors in the demand-side exploration. Similarly, in the systemside exploration, factors like an attitude of the health-care staff, ${ }^{21,24,26}$ delay in referral for diagnosis ${ }^{10,19,26}$ were found to be the major contributing factors. These factors might have bias selection as the included study's objectives are diverse, and the exploration was conducted in different types of TB patients. Although this is one of the major limitations of this review, the current synthesis for India is also found to be in a similar line with the global findings.

A study done by Datiko et $\mathrm{al}^{16}$ in Ethiopia (2020) narrated that delays in seeking care are associated with factors like low awareness about TB, rural residence, high stigma, gender, number and type of facilities visited, cost of seeking TB care, poverty, comorbidity with HIV, socioeconomic status and cultural barriers. As per the Subbaraman et al group, to receive the successful outcome in TB care cascade, the most important risk factors such as demographics (eg, age, gender), type of tuberculosis (eg, pulmonary, extrapulmonary, prior treatment history), microbiological susceptibility (eg, drug-resistant forms of TB), comorbidities (eg, HIV, diabetes), or other social factors (eg, living in migrant, urban slum, or indigenous communities) are important among others, which need to be addressed with topmost priority. ${ }^{8}$ Therefore, the NTEP evaluators will need to think beyond access and coverage of health-care services and systematically measure and improve monitoring of the diverse factors that are synthesized here from the included Indian studies. In the same line, the WHO European regional office also recommended developing a people-centered TB care system by 
emphasizing the financial and service care benefits at the optimal level. ${ }^{45}$ An expert panel made by Odone et al also recommended that TB prevention should address a complex mix of biological and social determinants. ${ }^{46}$ Because TB patients often face challenges beyond their disease, and that these challenges must be addressed in order to provide accessible diagnosis, treatment and care. Thus, the determinants identified in this review might provide a guiding principle for future research and for the NTEP program planners and policymakers on how to capture or monitor those determinants beyond the health system level for universal TB care.

Looking at the National Strategic Plan (NSP) for TB elimination 2017-2025, ${ }^{5}$ India must start to seriously tackle the key determinants of TB, especially poverty, addictions, which have been clearly linked with TB and its mortality. The issues of stigma, financial constraints will require intersectoral collaboration among multiple sectors, including the community. This review also justifies the concept of TB inclusion in social protection programs with a focus on prevention and protecting patients from impoverishment, as indicated by Pai et al. ${ }^{47}$ Further, India must address the major factors from the system side that have already been identified in the TB care cascade as part of the delay, such as multiple consultations or getting bounced between the private and/or informal sectors and public sectors. Yet, the unanswered question in this review is who is accountable for addressing these associated factors, whether the scope of the NTEP program or all other public health programs should converge and address collaboratively. The factors identified in this review such as poverty, myths/beliefs, addictions involve a strong socio-economic context and require long-term interventions; thus, efforts like "Health in All Policies (HiAP)"48,49 might be the way forward and recommended to the country like India.

\section{Conclusion}

This systematic literature review provides an insight into different factors from the system-side (health workforce, institutional) and the demand-side (individual, societal) contributing towards the efficient TB care cascade model in India. The prime factors reflected in most of the studies were socio-economic condition, disease awareness, myths/ beliefs, addictions among the demand-side factors and accessibility, an attitude of the health-care staff, delay in referral for diagnosis among the system-side factors. Although none of the Indian studies captured all the factors comprehensively, it has been recommended that future care cascade studies consider all these factors to understand the cascade outcome. Further, it has been recommended that NTEP evaluators also need to be concerned about these diverse factors in their assessment as some of them affects to outcome indicators. Further, the accountability of addressing these diverse factors needs to be determined for enhancing the TB care cascade.

\section{Disclaimer}

The US Agency for International Development administers the US foreign assistance program providing economic and humanitarian assistance in more than 80 countries worldwide. This study is made possible by the generous support of the American people through the United States Agency for International Development (USAID). The contents are the responsibility of the authors and do not necessarily reflect the views of USAID or the United States Government.

\section{Data Sharing Statement}

All relevant data that supports the findings of this study are within the manuscript.

\section{Ethics Approval and Consent to Participate}

Ethics approval for this study is not required, as this does not involve any human/animal participants. This is secondary in nature.

\section{Acknowledgments}

We wish to thank the team of experts from the Indian Institute of Public Health Gandhinagar for providing valuable inputs and feedbacks to the final draft of the manuscript. We would like to thank the World Health Partners (WHP) for their continuous support in the Closing the Gaps in TB Care Cascade (CGC) project. We express our sincere thanks to our donor - USAID New Delhi, India, for funding this study as a part of the larger project, namely, Closing the gaps in the TB care cascade.

\section{Author Contributions}

All authors contributed equally to the development of this study. All authors contributed to data analysis, drafting or revising the article, have agreed on the journal to which the article will be submitted, gave final approval of the version to be published, and agree to be accountable for all aspects of the work. 


\section{Funding}

This study is made possible by the generous support of the American People through the United States Agency for International Development (USAID). The work described in this article was implemented under the USAID Closing the gaps in TB Care Cascade Project, managed by World Health Partners under the terms of Cooperative Agreement Number 72038620CA00012. Staff of the funding agency critically reviewed the draft and offered comments to improve the paper.

\section{Disclosure}

The authors report no conflicts of interest in this work.

\section{References}

1. World Health Organization. Global Tuberculosis Report 2020 Geneva; 2020. Available from: https://www.who.int/publications/i/ item/9789240013131. Accessed July 23, 2021.

2. Central TB Division. India TB Report 2021. New Delhi; 2021. Available from: https://tbcindia.gov.in/index1.php?lang=1\&level= $1 \&$ sublinkid=4160\&lid=2807. Accessed July 23, 2021.

3. Singh S, Kumar S. Tuberculosis in India: road to elimination. Int $J$ Prev Med. 2019;10(1):114. doi:10.4103/ijpvm. IJPVM $492 \_17$

4. World Health Organization (WHO). The End TB strategy:Global strategy and targets for tuberculosis prevention, care and control after 2015.Available from: https://www.who.int/tb/strategy/End_TB_ Strategy.pdf. Accessed Feb20, 2021.

5. Ministry of Health and Family Welfare. National strategic plan for Tuberculosis: 2017-25 elimination by 2025. New Delhi; 2017. Available from: https://tbcindia.gov.in/WriteReadData/NSP\%20Draft \%2020.02.2017\%201.pdf. Accessed July 23, 2021.

6. Bhardwaj AK. Tuberculosis control programme from NTCP to RNTCP to NTEP. Indian J Community Heal. 2020;32(3):469-470. doi:10.47203/IJCH.2020.v32i03.001

7. Ku CC, Chen CC, Dixon S, Lin HH, Dodd PJ. Patient pathways of tuberculosis care-seeking and treatment: an individual-level analysis of National Health Insurance data in Taiwan. BMJ Glob Health. 2020;5:2187.

8. Subbaraman R, Jhaveri T, Nathavitharana RR. Closing gaps in the tuberculosis care cascade: an action-oriented research agenda. $J$ Clin Tuberc Other Mycobact Dis. 2020;19:100144. doi:10.1016/j. jctube.2020.100144

9. Subbaraman R, Nathavitharana RR, Mayer KH, et al. Constructing care cascades for active tuberculosis: a strategy for program monitoring and identifying gaps in quality of care. PLoS Med. 2019;16(2): e1002754. doi:10.1371/journal.pmed.1002754

10. Mistry N, Lobo E, Shah S, Rangan S, Dholakia Y. Pulmonary tuberculosis in Patna, India: durations, delays, and health care seeking behaviour among patients identified through household surveys. $J$ Epidemiol Glob Health. 2017;7(4):241-248. doi:10.1016/j. jegh.2017.08.001

11. Subbaraman R, Nathavitharana RR, Satyanarayana S, et al. The tuberculosis cascade of care in India's public sector: a systematic review and meta-analysis. PLOS Med. 2016;13(10):e1002149. doi:10.1371/journal.pmed.1002149

12. Mbuthia GW, Olungah CO, Ondicho TG. Health-seeking pathway and factors leading to delays in tuberculosis diagnosis in West Pokot County, Kenya: a grounded theory study. PLoS One. 2018;13(11): e0207995. doi:10.1371/journal.pone.0207995
13. World Health Organization. Standards for TB Care in India. New Delhi; 2014. Available from: https://tbcindia.gov.in/showfile.php?lid= 3061. Accessed July 23, 2021.

14. Government of India. Nikshay: TB surveillance under National Tuberculosis Elimination Programme. Ministry of Health and Family Welfare. 2020 [cited November 23, 2020]. Available from: https://nikshay.in/. Accessed July 23, 2021.

15. European Patient's' Academy on Therapeutic Innovations. Risk factors in health and disease. 2017. Available from: https://www.malta healthnetwork.org/wp-content/uploads/2017/07/Risk-factors-inhealth-and-disease.pdf. Accessed October 12, 2020.

16. Datiko DG, Jerene D, Suarez P. Patient and health system delay among TB patients in Ethiopia: nationwide mixed method cross-sectional study. BMC Public Health. 2020;20(1):1-10. doi:10.1186/s12889-020-08967-0

17. Bhattacharya T, Ray S, Biswas P, Das D. Barriers to treatment adherence of tuberculosis patients: a qualitative study in West Bengal, India. Int $J$ Med Sci Public Health. 2018;7(5):1. doi:10.5455/ijmsph.2018.0102220022018

18. Bagchi S, Ambe G, Sathiakumar N. Determinants of poor adherence to anti-tuberculosis treatment in Mumbai, India. Int J Prev Med. 2010;1:223-232.

19. McArthur E, Bali S, Khan A. Socio-cultural and knowledge-based barriers to tuberculosis diagnosis for women in Bhopal, India. Indian J Community Med. 2016;41(1):62. doi:10.4103/0970-0218.170990

20. Shewade HD, Kokane AM, Singh AR, et al. Provider reported barriers and solutions to improve testing among tuberculosis patients 'eligible for drug susceptibility test': a qualitative study from programmatic setting in India. PLoS One. 2018;13(4):e0196162. doi:10.1371/journal.pone.0196162

21. Deshmukh RD, Dhande DJ, Sachdeva KS, et al. Patient and provider reported reasons for lost to follow up in MDRTB treatment: a qualitative study from a drug resistant TB centre in India. PLoS One. 2015;10(8):e0135802. doi:10.1371/journal.pone.0135802

22. Shewade D, Kokane AM, Singh AR, et al. High pre-diagnosis attrition among patients with presumptive MDR-TB: an operational research from Bhopal district, India. BMC Health Serv Res. 2017;17(1):249. doi:10.1186/s12913-017-2191-6

23. Shringarpure KS, Isaakidis P, Sagili KD, Baxi RK. Loss-to-follow-up on multidrug resistant tuberculosis treatment in Gujarat, India: the WHEN and WHO of It. PLoS One. 2015;10(7):e0132543. doi:10.1371/journal.pone. 0132543

24. Valvi C, Chandanwale A, Khadse S, et al. Delays and barriers to early treatment initiation for childhood tuberculosis in India. Int $J$ Tuberc Lung Dis. 2019;23(10):1090-1099. doi:10.5588/ijtld.18.0439

25. Nimbarte SB, Wagh V, Selokar D. Health seeking behaviour among pulmonary tuberculosis patients in rural part of central India. Int J Biomed. 2011;2:394-397.

26. Mistry N, Rangan S, Dholakia Y, Lobo E, Shah S, Patil A. Durations and delays in care seeking, diagnosis and treatment initiation in uncomplicated pulmonary tuberculosis patients in Mumbai, India. PLoS One. 2016;11(3):e0152287. doi:10.1371/journal.pone.0152287

27. Velavan A, Purty AJ, Shringarpure K, et al. Tuberculosis retreatment outcomes and associated factors: a mixed-methods study from Puducherry, India. Public Health Action. 2019;8(4):187-193. doi:10.5588/pha.18.0038

28. Helfinstein S, Engl E, Thomas BE, et al. Understanding why at-risk population segments do not seek care for tuberculosis: a precision public health approach in South India. BMJ Glob Health. 2020;5(9):e002555.

29. Shewade HD, Govindarajan S, Thekkur P, et al. MDR-TB screening in a setting with molecular diagnostic techniques: who got tested, who didn't and why? Public Health Action. 2015;5:132-139.

30. Singhi L, Sagili KD, Sharath BN, et al. Non-response to first-line anti-tuberculosis treatment in Sikkim, India: a risk-factor analysis study. Public Health Action. 2019;8(4):162-168. doi:10.5588/ pha. 18.0026 
31. Dhaked S, Sharma N, Chopra KK, Khanna A. Barriers and challenges in seeking healthcare by pediatric tuberculosis patients attending DOTS centers in urban areas of Delhi. MAMC J Med Sci. 2019;5 (1):8. doi:10.4103/mamcjms.mamcjms 4318

32. Thomas BE, Suresh C, Lavanya J, et al. Understanding pretreatment loss to follow-up of tuberculosis patients: an explanatory qualitative study in Chennai, India. BMJ Glob Health. 2020;5:1974.

33. Van Ness SE, Chandra A, Sarkar S, et al. Predictors of delayed care seeking for tuberculosis in southern India: an observational study. BMC Infect Dis. 2017;17(1):567. doi:10.1186/s12879-017-2629-9

34. Ts L, Patil S; Secretary of Jan Swasthya Sahyog. Predictors of tuberculosis treatment outcomes among a retrospective cohort in rural, Central India. $J$ Clin Tuberc Other Mycobact Dis. 2018;12:41-47. doi:10.1016/j.jctube.2018.06.005

35. Paul D, Busireddy A, Nagaraja SB, et al. Factors associated with delays in treatment initiation after tuberculosis diagnosis in two districts of India. PLoS One. 2012;7(7):e39040. doi:10.1371/journal. pone.0039040

36. Tripathy JP, Srinath S, Naidoo P, Ananthakrishnan R, Bhaskar R. Is physical access an impediment to tuberculosis diagnosis and treatment? A study from a rural district in North India. Public Health Action. 2013;3(3):235-239. doi:10.5588/pha.13.0044

37. Tamhane A, Sathiakumar N, Vermund S, Kohler CL, Karande A, Ambe G. Pulmonary tuberculosis in Mumbai, India: factors responsible for patient and treatment delays. Int J Prev Med. 2012;3:569.

38. Yerramilli A, Narreddy S, Anisetti RN, Grace KA, Rakuditti S. Patient's perceptions of barriers to tuberculosis care in private sector in India. Open Forum Infect Dis. 2019;6(Supplement_2):S497-8. doi:10.1093/ofid/ofz360.1236

39. Yellappa V, Lefèvre P, Battaglioli T, Devadasan N, Van Der Stuyft P. Patients pathways to tuberculosis diagnosis and treatment in a fragmented health system: a qualitative study from a south Indian district. BMC Public Health. 2017;17(1):635. doi:10.1186/s12889-017-4627-7

40. Vijay S, Kumar P, Chauhan LS, Vollepore BH, Kizhakkethil UP, Rao SG. Risk factors associated with default among new smear positive TB patients treated under DOTS in India. PLoS One. 2010;5(4):e10043. doi:10.1371/journal.pone.0010043
41. Bhattacharya Chakravarty A, Rangan S, Dholakia Y, et al. Such a long journey: what health seeking pathways of patients with drug resistant tuberculosis in Mumbai tell us. PLoS One. 2019;14(1): e0209924. doi:10.1371/journal.pone.0209924

42. Kulkarni PY, Kulkarni AD, Akarte SV, Bhawalkar JS, Khedkar DT, Sadan S. Treatment seeking behavior and related delays by pulmonary tuberculosis patients in E-ward of Mumbai Municipal Corporation, India. Int $J$ Med Public Health. 2013;3(4):286. doi:10.4103/2230-8598.123474

43. Konda S, Melo C, Giri P, Behera A. Determinants of delays in diagnosis and treatment of pulmonary tuberculosis in a new urban township in India: a cross-sectional study. Int J Med Sci Public Health. 2014;3(2):140. doi:10.5455/ijmsph.2013.011120131

44. Sreeramareddy CT, Qin ZZ, Satyanarayana S, Subbaraman R, Pai M. Delays in diagnosis and treatment of pulmonary tuberculosis in India: a systematic review. Int J Tuberc Lung Dis. 2014;18(3):255-266. doi: $10.5588 /$ ijtld. 13.0585

45. World Health Organization Regional Office for Europe. A people-centred model of TB care. Copenhagen, Denmark; 2017. Available from: http://www.euro.who.int/. Accessed July 23, 2021.

46. Odone A, Roberts B, Dara M, Van Den Boom M, Kluge H, McKee M. People- and patient-centred care for tuberculosis: models of care for tuberculosis. Int J Tuberc Lung Dis. 2018;22(2):133-138. doi:10.5588/ijtld.17.0608

47. Pai M, Bhaumik S, Bhuyan SS. India's plan to eliminate tuberculosis by 2025 : converting rhetoric into reality. BMJ Glob Health. 2017;2 (2):e000326. doi:10.1136/bmjgh-2017-000326

48. World Health Organization (WHO). Health in All Policies (HiAP) framework for country Action. Geneva; 2014. Available from: https:// www.who.int/healthpromotion/hiapframework.pdf. Accessed July 23, 2021.

49. Synnevåg ES, Amdam R, Fosse E. Legitimising inter-sectoral public health policies: a challenge for professional identities? Int J Integr Care. 2019;19(4):9. https://www.ijic.org/articles/10.5334/ijic.4641/
Risk Management and Healthcare Policy

\section{Publish your work in this journal}

Risk Management and Healthcare Policy is an international, peerreviewed, open access journal focusing on all aspects of public health, policy, and preventative measures to promote good health and improve morbidity and mortality in the population. The journal welcomes submitted papers covering original research, basic science, clinical \& epidemiological studies, reviews and evaluations,

\section{Dovepress}

guidelines, expert opinion and commentary, case reports and extended reports. The manuscript management system is completely online and includes a very quick and fair peer-review system, which is all easy to use. Visit http://www.dovepress.com/testimonials.php to read real quotes from published authors. 